\title{
Clinical Significance of Selected Chemokines in Thyroid Cancer
}

\author{
ANGELIKA MIRONSKA ${ }^{1}$, MARTA $Ł U K A S Z E W I C Z-Z A J A C{ }^{1}$ and BARBARA MROCZKO ${ }^{1,2}$ \\ ${ }^{1}$ Department of Biochemical Diagnostics, Medical University of Bialystok, Bialystok, Poland; \\ ${ }^{2}$ Department of Neurodegeneration Diagnostics, Medical University of Bialystok, Bialystok, Poland
}

\begin{abstract}
Thyroid cancer (TC) is a common malignancy of the endocrine system. The global incidence of TC has increased dramatically in recent years. The available tumor biomarkers are not specific to TC and therefore finding new markers which could be helpful in the diagnostic process, prognosis and treatment of TC patients is a great challenge facing present and future researchers. Chemokines are small chemotactic proteins which play a significant role in the migration of leukocytes to many sites of the inflammatory process. It has been suggested that these molecules are able to promote cancer development by mediating inflammation. This paper presents the general structure of chemokines and their receptors as well as their potential significance in TC. The final aspect of this review is a summary of current knowledge and research results concerning the potential significance of selected chemokines and their specific receptors as candidates for novel tumor markers of TC.
\end{abstract}

Thyroid cancer. Thyroid is found at the base of the neck next to the trachea. The most important function of this gland involves the secretion of hormones that are responsible for controlling metabolism, heart rate and blood pressure (1). Thyroid cancer is the fastest growing endocrine malignancy, constituting approximately $1-2 \%$ of all cancer cases diagnosed each year $(1,2)$. Unfortunately, detection of this cancer occurs relatively late due to non-specific symptoms in the early stages of the disease. Recent epidemiological studies have revealed that the incidence of TC has increased significantly during the last 5 years (3). Many investigations have indicated that this cancer may originate from follicle cells or C-cells, which produce calcitonin. Follicular cellderived thyroid cancers can be classified into papillary

Correspondence to: Barbara Mroczko, Department of Neurodegeneration Diagnostics, Medical University of Bialystok, Bialystok, Poland, Waszyngtona 15 a, 15-269 Bialystok, Poland. Tel.: +48 858318785, Fax +48 858318585, e-mail: mroczko@umb.edu.pl

Key Words: Chemokines, receptor, thyroid, tumor, review. thyroid cancer, follicular thyroid cancer, poorly differentiated thyroid cancer and undifferentiated (anaplastic) thyroid cancer. Malignancy originating from C-cells is called medullary thyroid cancer (MTC) (3). Major risk factors for TC include a family history of cancer or any other thyroid disease, as well as radiation administered in the region of both head and neck. Additionally, other risk factors affect females, since TC incidence is higher in women. Moreover, the disease is more predominant in Caucasian and Asian populations in comparison to African Americans $(1,4)$. A number of clinical investigations have suggested that the increasing incidence of TC is related to the enhancement of available imaging methods, which results in the incidental detection of thyroid nodules.

Symptoms of TC include difficulty in swallowing and breathing as well as painful or painless tumefaction of the neck. Other significant symptoms are cryptogenic hoarseness or a change in voice quality, which should be readily examined once detected $(4,5)$.

Diagnosis of thyroid cancer. Thyroid cancer diagnosis is a complex process. It commonly starts with a routine physical examination and blood tests, such as the measurement of thyroid stimulating hormone (TSH), thyroid hormones $\left(\mathrm{T}_{3}\right.$ and $\mathrm{T}_{4}$ ), thyroglobulin ( $\mathrm{Tg}$ ) and thyroglobulin antibody ( $\mathrm{TgAb}$ ) levels. It should be mentioned that these parameters are required in the diagnosis of all thyroid diseases and they are not specific to TC since their levels only provide information about thyroid function. Therefore, these laboratory tests assist in cancer diagnosis, but their main diagnostic significance concerns the monitoring of the progression of this malignancy as well as the treatment of TC patients (5).

Classical tumor markers used in TC diagnosis are Tg and calcitonin. Relevant research has revealed that serum calcitonin concentration is elevated in patients with medullary thyroid cancer. Furthermore, some studies have indicated that MTC cells have the ability to secrete the carcinoembryonic antigen (CEA), whose increased serum concentrations are associated with advanced stages of TC (6). 
Treatment guidelines for TC patients depend on the histological type and stage of the tumor at the time of initial diagnosis. Commonly, therapy comprises various options, such as surgery, including hemithyroidectomy, near-total thyroidectomy and total thyroidectomy. The remaining therapies rely on the use of radioactive iodine $\left({ }^{131} \mathrm{I}\right)$ and tyrosine kinase inhibitors (TKIs) $(1,3)$.

Chemokines and their receptors - general characteristics. Chemokines form a large family of small chemotactic cytokines which may be released mainly by leukocytes spontaneously or following induction. These molecules are able to transmit signals through the activation of specific $\mathrm{G}$ protein receptors located on the surface of target cells, leading to distinct cellular responses, such as adhesion, chemotaxis and migration (7). Their predominant role is to keep the immune system efficient by recruiting leukocytes in a timely and spatial manner. Chemokines are also involved in the regulation of many leukocyte functions, such as growth and activation. In addition, these molecules play a role in physiological and pathological processes, such as angiogenesis and autoimmune responses $(7,8)$.

Chemokines are generally identified by their systematic name, which consists of the group of chemokine, followed by the letter " $L$ " for the ligand or letter " $R$ " for the receptor. Receptors located on the cell surface can be activated by multiple chemokine ligands. Moreover, many chemokines have the ability to activate more than one receptor (9). The general classification is presented in Figure $1(10,11)$. To date, more than 50 chemokines have been discovered. They are grouped into four main classes: $\mathrm{CXC}, \mathrm{CC}, \mathrm{CX} 3 \mathrm{C}$ and $\mathrm{C}$, based on the position of cysteine in the N-terminal part (10). The CXC group (alpha) is subdivided into ELR+ and ELR- chemokines, depending on the presence or absence of the "tripeptide glutamic acidleucine-arginine", abbreviated to "ELR", motif. Chemokines that belong to the ELR+ group are angiogenic (CXCL1-3 and CXCL5-8), while the ones comprising the ELR-group are able to inhibit angiogenesis (CXCL4 and CXCL9-11). The CC group (beta) comprises chemokines with two adjacently positioned aminoterminal cysteines. It has also been indicated that they are able to chemoattract the majority of leukocytes, such as T or B cells, monocytes or mast cells. The $\mathrm{C}$ group (gamma) is characterised by a single part of aminoterminal cysteine, whereas the $\mathrm{CX} 3 \mathrm{C}$ group (delta) includes chemokines with three amino acids, located between the first two cysteines (12).

Chemokines have the ability to interact with specific receptors that belong to the $G$ Protein-Coupled Receptor (GPCR) family. It has been revealed that these proteins are seven-transmembrane $\mathrm{N}$-terminus structurally related receptors, coupled to G-proteins. Approximately 20 chemokine receptors have been investigated to date (13)
The role of chemokines and their specific receptors in cancer. Chemokines play a significant role in inflammation by regulating cellular migration, particularly of leukocytes (13). The tumor microenvironment is regulated by a number of specific intracellular interactions between the tumor and host cells. Despite the role played by the chemokines in the immune system, their function in tumor growth is associated with their participation in the inflammation process, which may promote cancer development and progression. The tumorigenic role of chemokines and their receptors is presented in Figure 2 (14).

Some studies have investigated the link between cancer and inflammation. It has been suggested that tumor cells are able to secrete a variety of inflammatory mediators, leading to the promotion and regulation of both tumor growth and metastasis. It has been demonstrated that these mediating molecules may be members of specific groups, such as cytokines or other chemokines (15). Similarly to growth factors, cytokines have a direct impact on tumor growth or the survival of metastatic seeds, whereas chemokines are responsible for the recruitment of immune and stromal cells as well as for providing tumor support (15).

CXCL8 is the most extensively investigated chemokine. It has been proven that this protein can influence different cell populations. CXCL8 is responsible for intensifying the migration activity of dendritic and mast cells. (16). The direct impact of CXCL8 on vascular endothelial cells is concerned with its participation in enhancing the endurance and survival of these cells In fact, the ability of CXCL8 to intensify angiogenesis pertains to the up-regulation of matrix metalloproteinases, such as matrix metalloproteinase-2 (MMP-2) or matrix metalloproteinase-9 (MMP-9) in endothelial cells or even in tumor cells $(17,18)$. In addition, it has been demonstrated that a deficiency in CXCL12 or its receptor, CXCR4, in mice causes many vascular abnormalities (19). However, chemokines also possess the ability to inhibit the process of angiogenesis. Both CXCL4 and CXCL10 may suppress angiogenesis induced by VEGF as well as fibroblast growth factors $(11,20)$.

Cancer metastasis is a multi-step process involving local invasion, extravasation, and proliferation and growth, during which stage tumor cells disseminate from the location of a primary tumor to distant locations in the body. Metastasis is the main cause of death for most patients. Many investigations have shown that chemokines play an important role in cancer metastasis due to the tumor's ability to express chemokine receptors, which may direct cancer cells to specific anatomic locations where they start forming secondary tumors (21).

Research studies performed in humans have demonstrated that the increased expression of another chemokine, CXCR4, is associated with tumor metastasis in various types of tumors. The CXCL12/CXCR4 complex plays a significant role in tumor cell migration to different metastatic sites, as demonstrated in breast cancer and esophageal carcinoma (22, 


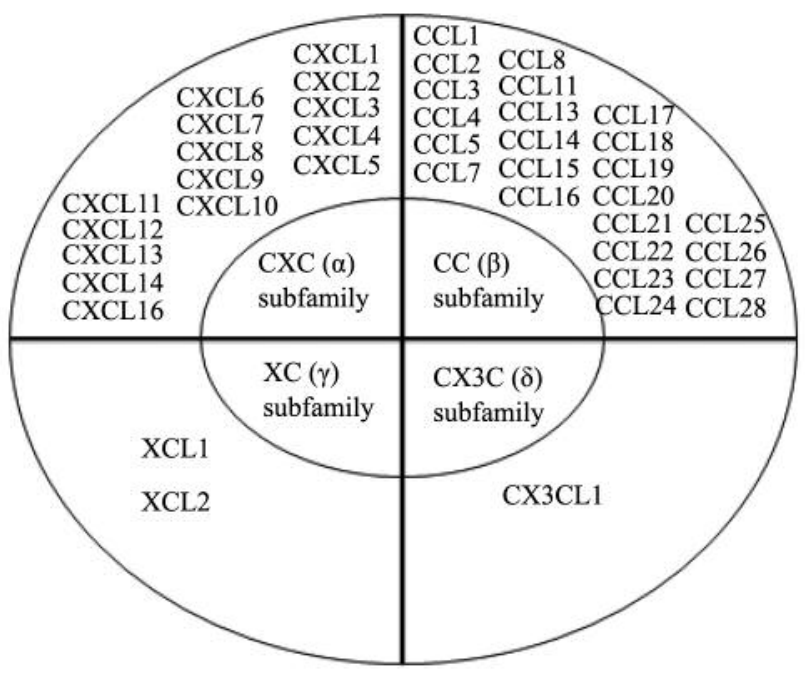

Figure 1. Classification of chemokines (adapted from 10, 11).

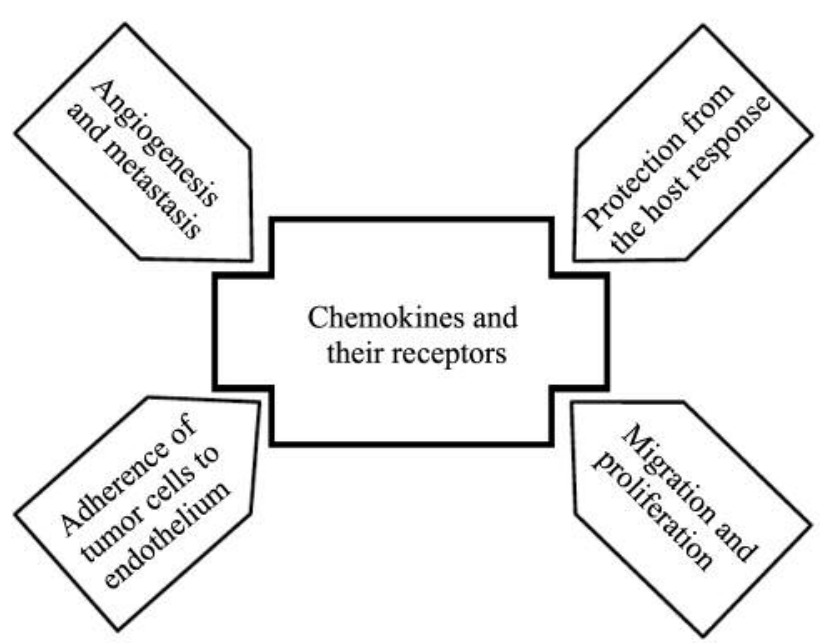

Figure 2. The tumorigenic role of chemokines and their receptors (adapted from 14).

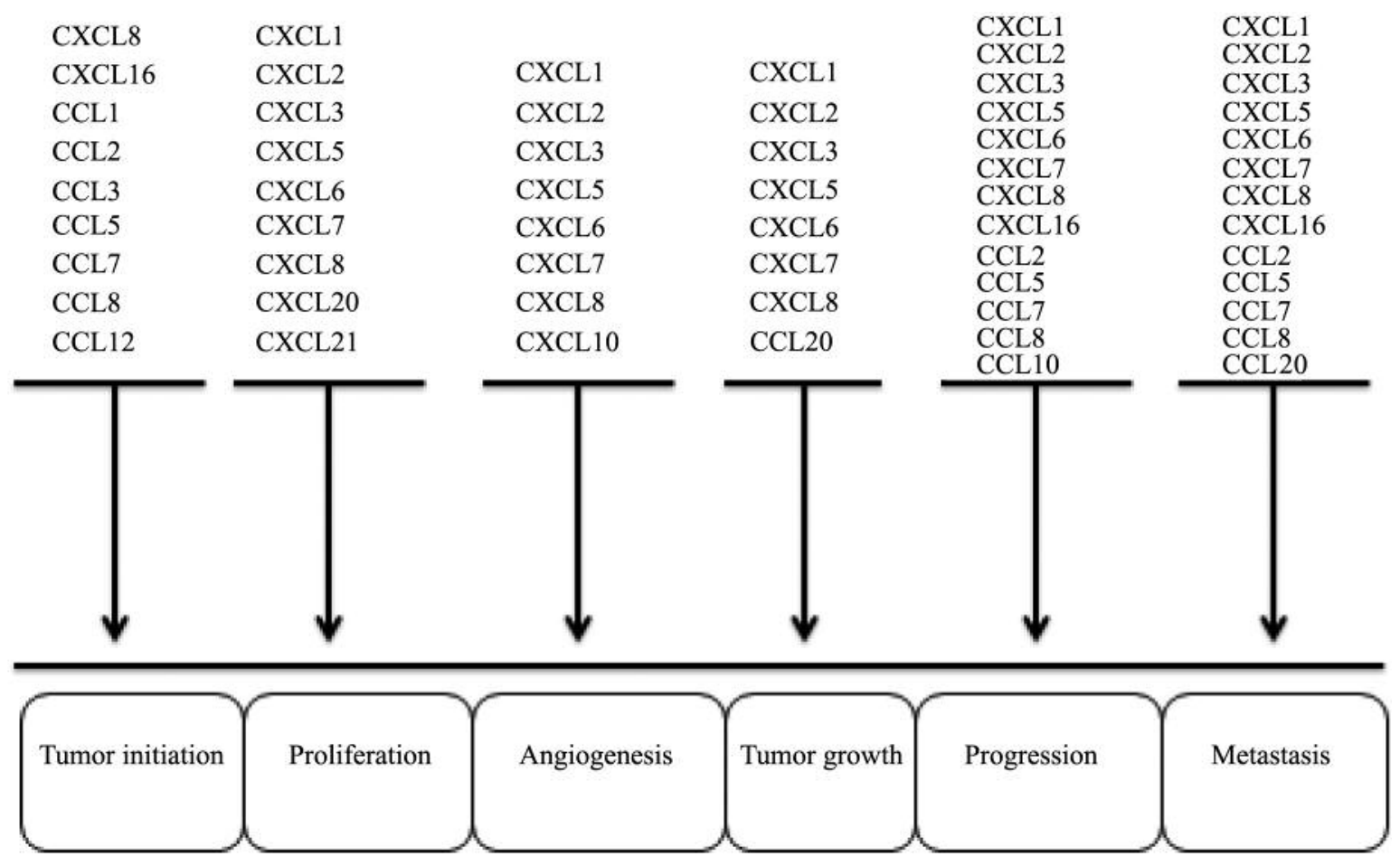

Figure 3. Chemokines involved in the development of thyroid tumor (adapted from 26).

23). Blocking CXCL12/CXCR4 has been shown to suppress metastasis from breast cancer to the lungs (24). Another complex, CCL21/CCR7, is involved in tumor cell migration to sentinel lymph nodes in various cancers, such as oesophageal carcinoma (22) and breast cancer (24). In addition, CCL21/CCR7 axis disruption may prevent lymph node metastasis, but only on condition that a primary tumor is detected at an early stage of the disease (25). 
The role of chemokines and their specific receptors in TC cancer. Clinical investigations have proven that a select group of chemokines as well as their specific receptors are involved in every stage of tumor development, including proliferation, migration, angiogenesis and metastasis. In addition, it has been demonstrated that these molecules are responsible for the communication between non-neoplastic and cancer cells, or that they protect the tumor from the host's response (14). It has been indicated that TC cells produce a number of chemokines as a result of Mitogenactivated protein kinase (MAPK) activation. Thyroid cells are able to produce various CXC chemokines, such as CXCL1, CXCL8/IL-8, CXCL9 or CXCL10, either in basal conditions or following specific stimulation. Selected chemokines involved in TC progression are presented in Figure 3 (26).

CXCL8 is the first chemokine that was identified to be secreted by thyroid cells, called thyrocytes. It is a cytokine with pro-inflammatory properties, produced mainly by leukocytes, but also by other cells, such as macrophages and epithelial cells. CXCL8 is a member of the CXC group with both angiogenic and angiostatic attributes. The biological effects of the chemokine are exerted through two receptors coupled to G-proteins, CXCR1 and CXCR2 (26). Some studies have shown positive expression of CXCL8 in human TC specimens, while it is absent from normal thyroid tissue, while CXCL8 concentrations are significantly higher in the sera of patients with TC in comparison to healthy controls. Furthermore, it has been revealed that serum concentrations of this chemokine are significantly elevated in patients with advanced stages (III and IV) of TC as compared to both healthy individuals and patients in the early stages of the disease (stages I and II) (26). In addition, a correlation has been revealed between CXCL8 expression and the presence of lymph node metastasis, as well as with more advanced TNM stages of TC (27). Taken together, these results may indicate the potential usefulness of CXCL8 as a marker of TC progression or aggressive TC $(26,27)$.

CCL20 is a member of the CC-chemokine group. It is a unique ligand, able to interact and activate the CCR receptor (14). Increased CCL20 expression has been found in various malignancies, such as pancreatic (28) and lung cancer (29). In addition, CCL20 expression has been found to correlate with tumor growth and metastasis. Some investigations have suggested a link between the high expression of CCL20 and poor prognosis in colorectal cancer patients (30). A study by Zeng et al., (30) has demonstrated higher CCR6 expression in TC cells in comparison to thyroid epithelial cells. The study also revealed that activation of CCR6 by CCL20 promoted the invasion and migration of TC cells. The authors suggested the potential significance of CCR6 blockage in the therapy of TC patients.
CXCL12, also named stromal cell-derived factor 1 (SDF1), is a chemokine which belongs to the CXC group. Originally it was identified in bone marrow stromal cells (31). This protein plays a role in many important processes, such as inflammation responses, tumor growth as well as metastasis (32). CXCR4 is a well-recognised receptor for CXCL12 $(33,34)$, whereas CXCR7 is a novel receptor for this ligand $(35,36)$. CXCR7 has been demonstrated to be expressed in several cancer cell lines, including TC (37). An immunohistochemical study performed by Zhen et al., (38) has showed that the expression of CXCL12 and its novel receptor, CXCR7, was higher in PTC tissue in comparison to nonmalignant thyroid tissue. In addition, the expression of this chemokine correlated with the presence of lymph node metastasis (38), collectively suggesting the potential significance of these proteins as PTC markers.

\section{Conclusion}

Chemokines are small proteins produced by leukocytes and tumor cells. Generally, these proteins have been shown to participate in the inflammation process, development of infections and in malignant diseases. In this review, we conducted an exhaustive literature search via the PubMed database to investigate the significance of chemokines in TC. Our search demonstrated that selected chemokines, as well as their specific receptors, may be involved in thyroid cancer development. It also indicated that chemokines are responsible for intensifying the processes of tumorigenesis at every stage of $\mathrm{TC}$, from tumor initiation, proliferation and growth to tumor metastasis.

\section{Conflicts of Interest}

None declared.

\section{Authors' Contribution}

The study design, manuscript preparation and literature search were performed by AM, MLZ, and BM.

\section{Acknowledgments}

The present project was supported by the Medical University of Bialystok, Poland (N/ST/ZD/18/010/2207; N/ST/ZD/18/011/2207).

\section{References}

1 Nguyen QT, Lee EJ, Huang MG, Park YI, Khullar A and Plodkowski RA: Diagnosis and treatment of Patients with Thyroid Cancer. Am Health Drug Benefits 8: 30-40, 2015. PMID: 25964831.

2 Lumachi F, Basso SMM and Orlando R: Cytokines, thyroid diseases and thyroid can-cer. Cytokine 50: 229-233, 2010. PMID: 20381375. DOI: 10.1016/j.cyto.2010.03.005

3 Knox MA: Thyroid nodules. Am Fam Physician 88: 193-196, 2013. PMID: 23939698. 
4 Cooper DS, Doherty GM, Haugen BR, Kloos RT, Lee SL, Mandel SJ, Mazzaferri EL, McIver B, Pacini F, Schlumberger M, Sherman SI, Steward DL and Tuttle RM: Ameri-can Thyroid Association (ATA) guidelines taskforce on thyroid nodules and differenti-ated thyroid cancer. Revised American Thyroid Association management guidelines for patients with thyroid nodules and differentiated thyroid cancer: the American Thyroid Association (ATA) guidelines taskforce on thyroid nodules and differentiated thyroid cancer. Thyroid 9: 1167-1214, 2009. PMID: 19860577 . DOI: 10.1089/thy.2009.0110

5 MedlinePlus. Thyroid cancer. Updated March 23, 2014. Available at: www.nlm.nih.gov/medlineplus/ency/article/001213

6 Machens A, Ukkat J, Hauotmann S and Drakke H: Abnormal carcinoembryonic antigen levels and medullary thyroid cancer progression. Arch Surg 142: 289-293, 2007. PMID: 17372055. DOI: $10.1001 /$ archsurg.142.3.289

7 Raman D, Sobolik-Delmaire T and Richmond A: Chemokines in health and disease. Exp Cell Res 317: 575-589, 2011. PMID: 21223965. DOI: 10.1016/j.yexcr.2011.01.005

8 Luster AD: Chemokines - chemotactic cytokines that mediate inflammation. N Engl J Med 338: 436-445, 1998. PMID: 9459648. DOI: 10.1056/NEJM199802123380706

9 Nomiyama H, Osada N and Yoshie O: Systematic classification of vertebrate chemokines based on conserved synteny and evolutionary history. Genes Cells 18: 1-16, 2013. PMID: 23145839. DOI: $10.1111 /$ gtc. 12013

10 Biswas SK, Sica A and Lewis CE: Plasticity of macrophage function during tumor pro-gression: regulation by distinct molecular mechanisms. J Immunol 180: 2011-2017, 2008. PMID: 18250403.

11 Rot A and von Andrian UH: Chemokines in innate and adaptive host defense: Basic chemokinese grammar for immune cells. Annu Rev Immunol 22: 891-928, 2004. PMID: 15032599. DOI: 10.1146/annurev.immunol.22.012703.104543

12 Vandercappellen J, Van Damme J and Struyf S: The role of CXC chemokines and their receptors in cancer. Cancer Lett 267: 226244, 2008. PMID: 18579287. DOI: 10.1016/j.canlet.2008.04.050

13 Palomino DC and Marti LC: Chemokines and immunity. Einstein 13: 469-473, 2015. PMID: 26466066. DOI: 10.1590/ S1679-45082015RB3438

14 Sun X, Cheng G, Hao M, Zheng J, Zhou X, Zhang J, Taichman RS, Pienta KJ and Wang J: CXCL12/CXCR4/CXCR7 chemokine axis and cancer progression. Cancer Metastasis Rev 29: 709-722, 2010. PMID: 20839032. DOI: 10.1007/s10555010-9256-x

15 Atretkhany KSN, Drutskaya MS, Nedospasov SA, Grivennikov SI and Kuprash DV: Chemokines, cytokines and exosomes help tumors to shape inflammatory microenvironment. Pharmacol Ther 168: 98-112, 2016. PMID: 27613100. DOI: 10.1016/ j.pharmthera.2016.09.011

16 Alfaro C, Sanmamed MF, Rodriguez-Ruiz ME, Teijeira A, Onate C, Gonzalez A, Ponz M, Schalper KA, Pérez-Gracia JL and Melero I: Interleukin-8 in cancer pathogenesis, treatment and follow-up. Cancer Treat Rev 60: 24-31, 2017. PMID: 28866366. DOI: $10.1016 /$ j.ctrv.2017.08.004

17 Li A, Varney ML, Valasek J, Godfrey M, Dave BJ and Singh RK: Autocrine role of interleukin-8 in induction of endothelial cell proliferation, survival, migration and MMP-2 production and angiogenesis. Angiogenesis 8: 63-71, 2005. PMID: 16132619. DOI: $10.1007 / \mathrm{s} 10456-005-5208-4$
18 Luca M, Huang S, Gershenwald JE, Singh RK, Reich R and Bar-Eli M: Expression of interleukin- 8 by human melanoma cells up-regulates MMP-2 activity and increases tu-mor growth and metastasis. Am J Pathol 151: 1105-1113, 1997. PMID: 9327744.

19 Tachibana K, Hirota S, Iizasa H, Yoshida H, Kawabata K, Kataoka Y, Kitamura Y, Matsushima K, Yoshida N, Nishikawa $\mathrm{S}$, Kishimoto $\mathrm{T}$ and Nagasawa $\mathrm{T}$ : The chemokine receptor CXCR4 is essential for vascularization of the gastrointestinal tract. Nature 393: 591-594, 1998. PMID: 9634237. DOI: $10.1038 / 31261$

20 Bachelder RE, Wendt MA and Mercurio AM: Vascular endothelial growth factor promotes breast carcinoma invasion in an autocrine manner by regulating the chemokine receptor CXCR4. Cancer Res 62: 7203-7206, 2002. PMID: 12499259.

21 Zlotnik A, Burkhardt AM and Homey B: Homeostatic chemokine receptors and organ-specific metastasis. Nat Rev Immunol 11: 597-606, 2011. PMID: 21866172. DOI: 10.1038/ nri3049

22 Ding Y, Shimada Y, Maeda M, Kawabe A, Kaganoi J, Komoto I, Hashimoto $\mathrm{Y}$, Miyake M, Hashida $\mathrm{H}$ and Imamura $\mathrm{M}$ : Association of CC chemokine receptor 7 with lymph node metastasis of esophageal squamous cell carcinoma. Clin Cancer Res 9: 3406-3412, 2003. PMID: 12960129.

23 Luker KE and Luker GD: Functions of CXCL12 and CXCR4 in breast cancer. Cancer Lett 238: 30-41, 2006. PMID: 16046252. DOI: 10.1016/j.canlet.2005.06.021.

24 Müller A, Homey B, Soto H, Ge N, Catron D, Buchanan ME, McClanahan T, Murphy E, Yuan W, Wagner SN, Barrera JL, Mohar A, Verástegui E and Zlotnik A: Involvement of chemokine receptors in breast cancer metastasis. Nature 410: 5056, 2001. PMID: 11242036. DOI: 10.1038/350650

25 Raman D, Baugher PJ, Thu YM and Richmond A: Role of chemokines in tumor growth. Cancer Lett 256: 137-165, 2007. PMID: 17629396. DOI: 10.1016/j.canlet.2007.05.013

26 Yapa S, Mulla O, Green V, England J and Greeman J: The role of chemokines in thy-roid carcinoma. Thyroid 27: 1347-1359, 2017. PMID: 28891394. DOI: 10.1089/thy.2016.0660

27 Liotti F, Collina F, Pone E, La Sala L, Franco R, Prevete N and Melillo RM: Interleukin 8, but not related chemokine CXCL1, sustains and autocrine circiut necessary for the properties and functions of thyroid cancer stem cells. Alpha Med Press 35: 135146, 2017. PMID: 27577959.

28 Rubie C, Frick VO, Ghadjar P, Wagner M, Grimm H, Vicinus B, Justinger C, Graeber S and Schilling MK: CCL20/CCL6 expression profile in pancreatic cancer. J Transl Med 8: 45, 2010. PMID: 20459729. DOI: 10.1186/1479-5876-8-45

29 Kirshberg S, Izhar U, Amir G, Demma J, Vernae F, Beider K, Shlomai Z, Wald H, Za-mir G, Shapira OM, Peled A and Wald O: Involvement of CCR6/CCL20/IL-17 axis in NSCLC disease progression. PLos One 6: e24856, 2011. PMID: 21949768. DOI: 10.1371/journal.pone.0024856

30 Zeng W, Chang H, Ma M and Yanwei L: CCL20/CCL6 promotes the invasion and mi-gration of thyroid cancer cells via NF-kappa B signaling-induced MMP-3 production. Exp Mol Pathol 97: 184-190, 2014. PMID: 24984269. DOI: 10.1016/ j.yexmp.2014.06.012

31 Bleul CC, Fuhlbrigge RC, Casasnovas JM, Aiuti A and Springer TA: A highly effica-cious lymphocyte chemoattractant, stromal cell-derived factor 1 (SDF-1). J Exp Med 184: 1101-1109, 1996. PMID: 9064327. DOI: 10.1084/jem.184.3.1101 
32 Marcuzzi E, Angioni R, Molon B and Calì B: Chemokines and chemokine receptors: Orchestrating tumor metastasization. Int $\mathrm{J}$ Mol Sci 20: E96, 2018. PMID: 30591657. DOI: 10.3390/ ijms 20010096

33 Caruz A, Samsom M, Alonso JM, Alcami J, Baleux F, Virelizier JL, Parmentier $M$ and Arenzana-Seisdedos F: Genomic organization and promoter characterization of human CXCR4 gene. FEBS Lett 426: 271-278, 1998. PMID: 9599023.

34 Gupta SK and Pillarisetti K: Cutting edge: CXCR4-Lo: molecular cloning and functional expression of a novel human CXCR4 splice variant. J Immunol 163: 2368-2372. 1999. PMID: 10452968.

35 Burns JM, Summers BC, Wang Y, Melikian A, Berahovich R, Miao Z, Penfold ME, Sunshine MJ, Littman DR, Kuo CJ, Kuo CJ, Wei K, McMaster BE, Wright K, Howard MC and Schall TJ: A novel chemokine receptor for SDF-1 and I-TAC involved in cell survival, cell adhesion, and tumor development. J Exp Med 203: 2201-2213, 2006. PMID: 16940167. DOI: 10.1084/ jem.20052144
36 Balabanian K, Lagane B, Infantino S, Chow KY, Harriague J, Moepps B, Arenzana-Seisdedos F, Thelen M and Bachelerie F: The chemokine SDF-1/CXCL12 binds to and signals through the orphan receptor RDC1 in T lymphocytes. J Biol Chem 280: 3576035766, 2005. PMID: 16107333. DOI: 10.1074/ jbc.M508234200

37 Zhang H, Yang L, Teng X, Liu Z, Liu C, Zhang L and Liu Z: The chemokine receptor CXCR7 is a critical regulator for the tumorigenesis and development of papillary thy-roidncarcinoma by inducing angiogenesis in vitro and in vivo. Tumor Biol 37: 24152423, 2016. PMID: 26383519. DOI:10.1007/s13277-015-4051-5

38 Zhen L, Sun DX, Teng XY, Xu WX, Meng XP and Wang BS: Expression of stromal derived factor 1 and CXCR7 in papillary thyroid carcinoma. Endocr Pathol 23: 247-253, 2014. PMID: 23070788. DOI: 10.1007/s12022-012-9223-x

Received April 24, 2019 Revised May 16, 2019 Accepted May 17, 2019 